\section{Up where the eagles fly}

\section{Rory Howlett}

Bird LIfe of Mountain and Upland. By Derek Ratcliffe. Cambridge University Press: 1991. Pp.255. £19.50, \$44.50.

THE upland regions of the British Isles support a splendid and diverse assemblage of birds. In Bird Life of Mountain and Upland, Derek Ratcliffe, former chief scientist of the British Nature Conservancy Council and experienced field ornithologist, surveys the distinctive avifaunas of the main upland habitats with a strong emphasis on the ecology and conservation of the species concerned.

Although the book may seem of only parochial interest, this is not so, as many of the issues raised are ones that concern ornithologists, conservationists and ecologists generally. Ratcliffe lists 66 British breeding birds that he considers to have a claim as upland species. (Upland is used here as a collective term for mountains, moorland and hills, of which there are several million hectares in Britain.) These include several spectacular raptors such as the golden eagle. Aquila chrysaetos, and the peregrine falcon, Falco peregrinus, whose breeding populations are said to be among the highest in Europe. Several species such as the ptarmigan, Lagopus mutus, the dotterel, Charadrius morinellus, and the snow bunting, Plectrophenax nivalis, Ratcliffe regards as 'relict' or 'fringe' species. Thus, "the strong emphasis of northern, tundra-breeding species in Britain and Ireland suggests that our upland avifauna owes its origin mainly to southwards displacement of bird assemblages from the Arctic and Boreal regions during the last glaciation."

Ratcliffe does an excellent job of explaining the relationship between the distribution and relative abundance of upland bird species, for many of which Britain is at the limit of their geographical range, and various environmental influences. Particular attention is given to the effects of climate, geology, human land use (afforestation, for example), availability of suitable habitat and topography. Grouping the upland regions into several main types - the sheep walks, the grouse moors, the deer forests, the flows, the maritime hills and the high tops - Ratcliffe succeeds admirably in giving the reader a flavour of their natural history, bird life and ecology.

A recurring theme in the book relates to the ecological factors, often mysterious, constraining the distribution of some of the rarer species to limited areas. A case in point is the chough, Pyrrhocorax pyrrhocorax, a distinctive member of the crow family more commonly found in Alpine regions. In Britain, the species is confined mainly to sea

cliffs on the western coastlines of Wales and Ireland. According to Ratcliffe, "the chough seems to exemplify a puzzling feature about many birds: they are essentially mobile creatures, potentially able to colonise new ground, yet the distribution of most species is markedly static and there is often an apparent resistance to spread beyond their wellestablished range." The same point is made in relation to the red kite, Milvus milvus, the buzzard, Buteo buteo, and the dotterel already mentioned. The ecological reasons for this resistance to spread are largely unknown, underlining the need for further research. Presumably it reflects, in part, the exquisite sensitivity of species' habitat requirements, which, until they are fully understood, will hamper attempts at conservation.

Ratcliffe gives a particularly lucid account of the steady recovery of the peregrine falcon in Britain over recent years, following the dramatic crash in the breeding population resulting from the effects of persistent orga-

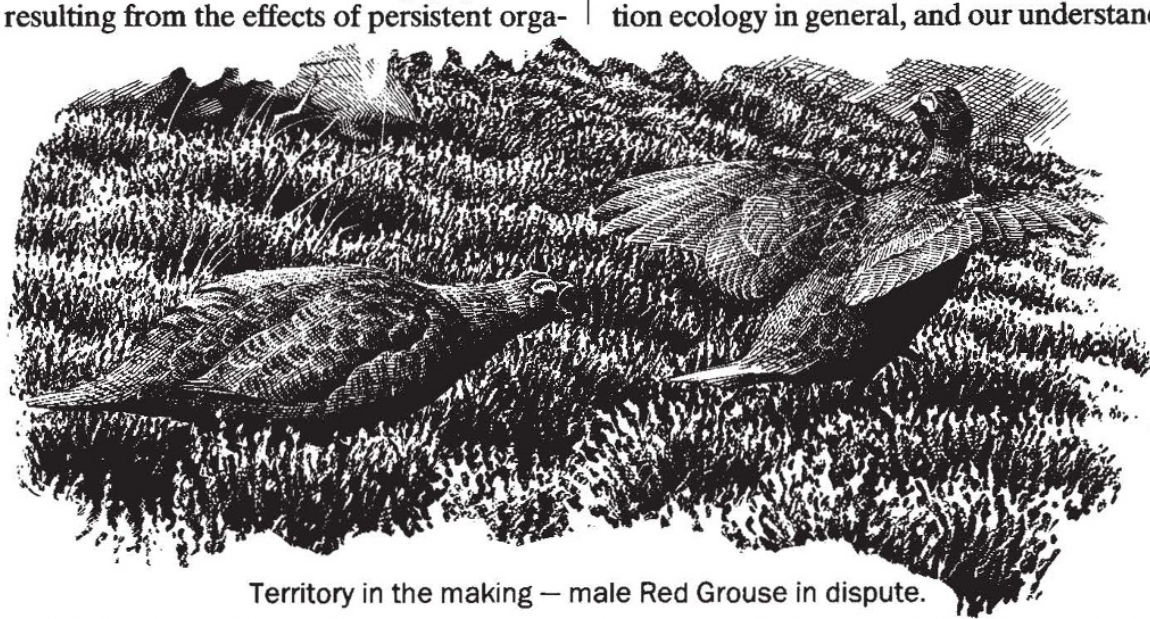

nochlorine insecticides. The crash was first detected by the British Trust for Ornithology in the 1950s. By 1963, when restrictions in the use of dieldrin insecticides began to take effect, the national population was down to 44 per cent of its pre-war level, which had been quite stable. By 1985 the population had made an almost complete recovery, which, according to Ratcliffe, "was final vindication of the case that the persistent organochlorines were the cause of the decline, and the prediction that their reduction as environmental contaminants would be followed by a matching reversal in the trend." Dieldrins have direct lethal effects on adult birds, whereas DDT, which Ratcliffe takes only to have been a secondary factor in the decline, reduces breeding performance through its deleterious effects on egg-shell development. Thus, "Dieldrin residues in Peregrines have declined to very low levels and while those of DDT and DDE are still moderate in some areas, they have not been sufficient to prevent population recovery."

The 'Glorious Twelfth' (of August) is an important date in the British social calendar, marking as it does the beginning of the annual grouse shoot. The economic importance of the red grouse - once celebrated as Britain's only endemic species, but now demoted to the lowly status of a southern race of the willow grouse, Lagopus lagopus - has made it the focus of many scientific studies over the years. After giving a potted history of the grouse shoot, Ratcliffe recounts how in 1911 the Committee of Inquiry on Grouse Disease published 'a lengthy report' blaming epidemics of mortality primarily on caecal infestation by the nematode threadworm Trichostrongylus tenuis, exacerbated by the poor quality of heather on some moors. As stated by Ratcliffe, this was one of the first intensive ecological studies of bird species ever carried out; a major recommendation was that there should be rotational burning of the grouse moor to optimize carrying capacity.

As is the case in other species dependent on one or a few food species, populations of red grouse exhibit regular cycles, and studies of their dynamics have played an important role in the development of animal population ecology in general, and our understand- ing of population regulation in particular. (Curiously, no mention is made of the work of V. C. Wynne-Edwards, whose thesis that red grouse have evolved adaptations to avoid overpopulation caused great controversy in population ecology because of its dependence on population-level, as against individual-level selection.) Despite decades of research, however, there remain many uncertainties, for example, about the reasons underlying long-term downward trends in the grouse population, and the possible consequences of climate change. Ratcliffe puts it this way: "There is no simple, all embracing explanation of the population changes in Red Grouse. The only general conclusion that can be drawn is that truth has many sides."

Bird Life of Mountain and Upland is a cut above the average bird book, and is the first in what promises to be an outstanding series on bird habitats of the British Isles. Although the book will be of use primarily to those with an interest in the avifauna of Britain, it is also a source of valuable insights into bird ecology and conservation, and would not look out of place on the library shelves of any university zoology department.

Rory Howlett is Book Review Editor of Nature. 